\title{
Principios de una hermenéutica feminista interreligiosa
}

Principles of an interreligious feminist hermeneutics

JUAN JOSÉ TAMAYO-ACOSTA [Da

\section{Resumen}

El objetivo de este artículo es ofrecer unos principios de hermenéutica feminista comunes al judaísmo, cristianismo e islam para superar el fundamentalismo, el patriarcalismo, el androcentrismo y el colonialismo, en que suele incurrir la lectura de los textos fundantes de las tres tradiciones, que sirvan de base para la organización, la disciplina, la moral y la doctrina teológica de las religiones.

Palabras-clave: Hermenéutica feminista. Hermenéutica de la sospecha. Hermenéutica decolonial. Textos sagrados.

\section{Abstract}

The objective of this paper is to offer some principles of feminist hermeneutics common to Judaism, Christianity and Islam to overcome fundamentalism, patriarchism, androcentrism and colonialism, in which the reading of the founding texts of the three traditions usually incurs, which serve base for the organization, discipline, morality and theological doctrine of religions.

Keywords: Feminist hermeneutics. Hermeneutics of suspicion. Decolonial hermeneutics. Sacred texts.

\footnotetext{
a Universidad Carlos III, Madrid, España; Doctor en Teología, e-mail: juanjotamayo@gmail.com
} 


\section{Introducción}

La mediación hermenéutica es inherente a la condición humana, como han puesto de relieve las diferentes filosofías del siglo XX. El ser humano vive y actúa, piensa y delibera, comprende y cree, juzga y experimenta, bajo el signo de la interpretación. El acto de comprender es interpretación, como lo es también experimentar en un sentido distinto del meramente pasivo, hasta el punto de que ser una persona "experimentada" consiste en haber conseguido ser un buen intérprete (cf. TAMAYO-ACOSTA, 2003). "Ser humano es actuar reflexivamente, decidir deliberadamente, comprender inteligentemente, experimentar plenamente. Lo sepamos o no, ser humano es ser un hábil intérprete" (TRACY, 1997, p. 23, subrayado mío). Nietzsche lleva esta idea al extremo hasta afirmar: "No existe los hechos; sólo existe la interpretación". Esto es aplicable a los textos sagrados de las religiones que, aun siendo considerados por los creyentes palabra de Dios, son ya interpretación de esa palabra divina en el tiempo y en la historia, una palabra expresada y transmitida en lenguaje humano con las categorías propias de la época en la que se redactaron los textos.

La hermenéutica ha sido la mediación a la que el ser humano ha recurrido siempre para resolver las dudas que le plantea la existencia, superar el estado de perplejidad en que se ve sumido cuando tiene que habérselas con situaciones que le desbordan y encontrar sentido a experiencias negativas. A través de ella ha conseguido descubrir los secretos de fenómenos de la naturaleza y de la cultura, cuyo significado se le escapaba, descifrar el significado de no pocas manifestaciones artísticas y literarias del más remoto pasado, contextualizar los textos sagrados y salvar la distancia cultural entre la época en que se escribieron los textos sagrados y la época en que son leídos (cf. TAMAYO-ACOSTA, 2003). La hermenéutica que voy a aplicar aquí en la lectura de los textos sagrados es la feminista con vistas a superar el fundamentalismo, el androcentrismo, el patriarcalismo y, por fin, el colonialismo. 


\section{Interpretación frente al fundamentalismo}

Las religiones viven sometidas de manera permanente al acoso de los fundamentalismos que ponen en peligro la convivencia y generan un clima de intolerancia e incluso de violencia fanática. El fundamentalismo no se manifiesta sólo en el terreno de las actitudes religiosas y de las prácticas sociopolíticas: el fenómeno fundamentalista suele darse en sistemas de creencias que se sustentan en textos revelados. Una de sus características es la renuncia a la hermenéutica como mediación entre los textos fundantes de las religiones y el contexto cultural en que se leen. Se cree que los textos sagrados han sido revelados directamente por Dios, son inmutables, tienen un solo sentido, el literal, y deben aplicarse a cada situación concreta en su literalidad (cf. TAMAYO-ACOSTA, 1998).

Tal concepción conduce derechamente a la uniformidad y al dogmatismo en las creencias y cierra todo camino al diálogo con las culturas de nuestro tiempo. El fundamentalismo propende a aislar el texto sagrado de su contexto socio-histórico y lo convierte en objeto devocional (cf. TAMAYOACOSTA, 1998). En los casos de las religiones judía, cristiana y musulmana estaríamos ante un acto de bibliolatría y de coranolatría, es decir, de adoración a la Biblia y el Corán como si se tratara de fetiches. El fundamentalismo lleva a leer los textos sagrados con los ojos de los muertos.

La mejor respuesta al fundamentalismo dentro de las religiones es la hermenéutica, clave de bóveda de toda teología. Sin la mediación hermenéutica, el discurso teológico deja de ser tal para convertirse en un acto de repetición de los textos del pasado, de reproducción del discurso oficial, de legitimación de la institución religiosa y de acatamiento acrítico de las declaraciones doctrinales emanadas del magisterio jerárquico - que se convierte en el único principio hermenéutico. Los teólogos y las teólogas deben estar dispuestos a afirmar con Steiner: "Lo que me interesa es la 'interpretación’ en cuanto que da a la palabra una vida que desborda el instante y lugar en que ha sido pronunciada y transcrita. La palabra 'intérprete' recoge todos los matices adecuados" (STEINER, 1978, p. 37).

En los libros sagrados de todas las religiones existen principios generales que enseñan el amor, la caridad, la libertad, la justicia y la igualdad 
de todos los seres humanos. En ellos se formula la regla de oro y se nos muestran ejemplos de hombres y mujeres portadores de esos valores en grado sumo que invitan al seguimiento, sobre todo de las fundadoras y reformadoras, de los fundadores y reformadores religiosos (cf. TAMAYOACOSTA, 2009). Pero también nos encontramos con textos que legitiman comportamientos de dudosa o nula moralidad, más aún, abiertamente inmorales. Ello exige promover dichos valores universales y cuestionar los comportamientos nada ejemplares atribuidos a Dios y practicados por quienes se declaran representantes suyos. Entre dichos valores se encuentran la emancipación de las mujeres, su libertad, la igualdad y justicia de género.

\section{Una hermenéutica de la sospecha como crítica al androcentrismo}

Muchos de los textos tenidos por sagrados en las religiones, las traducciones y las interpretaciones de estos son declaradamente androcéntricos, están al servicio del patriarcado y, más aún, fundamentan y legitiman el patriarcado social, político, familiar. La sospecha se justifica en que la autoría de la mayoría de los textos sagrados se atribuye a varones, la mayoría de los traductores e intérpretes son varones y en ellos las mujeres son marginales, invisibles. La hermenéutica feminista vigila y sospecha tanto de los textos originales como de las traducciones actuales y de sus intérpretes (cf. TAMAYO-ACOSTA, 2009).

La activista norteamericana por el sufragio de las mujeres y teóloga feminista Elizabeth Cady Stanton afirma - creo que certeramente - en La Biblia de las mujeres, publicada entre 1895 y 1898, que la Biblia ha sido escrita por hombres que nunca han visto a Dios ni han hablado con él:

No creo que ningún hombre viera nunca o hablara con Dios..., no creo que Dios inspirara el código mosaico o dijera a los historiadores lo que estos afirman que dijo sobre la mujer, pues todas las religiones sobre la faz de la tierra la degradan, y mientras la mujer acepte la posición que la asignan, su emancipación es imposible (STANTON, 1997, p. 40). 
$\mathrm{Y}$, sin embargo, añado yo, estos hombres se hacen pasar por videntes de Dios, representantes y portavoces suyos, y se convierten en masculinidades sagradas ungidas por la divinidad que legitima todos sus comportamientos por muy inmorales que sean.

A su vez, la interpretación crítica feminista va en busca de las tradiciones perdidas y de los relatos liberadores presentes en los textos androcéntricos y sus interpretaciones, que reconocen protagonismo a las mujeres. Hoy se habla de un pentateuco femenino formado por los libros de Rut, Judit, Ester, Cantar de los Cantares y Eclesiastés. Dicha interpretación busca un lenguaje inclusivo en la traducción de los textos. Las y los lingüistas feministas proporcionan pistas para descubrir el funcionamiento sexista del lenguaje. He aquí algunas: el lenguaje sexista produce invisibilidad o marginalidad lingüística de las mujeres (tiende a utilizar el genérico "hombre", alegando que incluye a hombres y mujeres); relativiza y trivializa las aportaciones de las mujeres; describe a estas como personas inferiores, subalternas y dependientes de los varones; las define a través de imágenes y roles estereotipados: madre, esposa, sumisa, recatada, ayuda para el varón. He aquí todavía tres ejemplos: el relato de la creación de la mujer de una costilla de Adán en la Biblia hebrea; los códigos domésticos de las cartas a Timoteo y a Efesios en las Escrituras cristianas; el texto coránico 4,34, que, según la mayoría de las traducciones al castellano, ordena pegar a las mujeres de las que se tema (solo por el hecho del temor de que se rebelen) (cf. TAMAYO-ACOSTA, 2003).

La hermenéutica feminista valora el significado de los textos sagrados para la comunidad de fe que los lee, interpreta y vive, pero cree que los textos patriarcales y las tradiciones sexistas no pueden estar dotados de la autoridad de revelación divina. Examina y cuestiona los textos opresores por su sexismo, racismo, colonialismo y militarismo. Muestra la relación entre los textos sagrados patriarcales y los estereotipos culturales y patriarcales de cada época. Los primeros vienen a reforzar la sumisión patriarcal. Este modo de hacer hermenéutica constata que textos neutrales e incluso positivos pueden reforzar las estructuras patriarcales al ser utilizados, proclamados o enseñados para inculcar valores represivos. Por ejemplo, aplicar a una mujer que sufre la violencia del marido el texto evangélico de cargar con la cruz y sufrir como lo hizo Cristo como justificación para salvar el matrimonio que se tambalea. 
Incluso el mandamiento del amor al prójimo, presente en todas las religiones, puede convertirse en opresivo y destructivo para las mujeres en una cultura patriarcal que utiliza a estas para servir, sacrificarse por los demás, atender a las personas mayores, enfermas, discapacitadas de la familia, al marido, a los hijos, en una palabra, para convertirlas en esclavas (Cf. TAMAYOACOSTA, 2003).

Esto es extensible a los preceptos evangélicos del amor al enemigo y del perdón hasta setenta veces siete, es decir siempre, que ordena el evangelio. ¿Cómo una mujer agredida, maltratada, violentada, violada, puede perdonar y amar al agresor, al violador, al maltratador? Tal actitud llevaría a justificar el mantenimiento de la agresión sin límites. La propia ética del cuidado, que es un imperativo universal a ser seguido por hombres y mujeres, aplicada solo a las mujeres constituye un ejemplo de sobrecarga para estas, frente a los varones, a quienes se exime de esa tarea.

\section{La crítica de las imágenes patriarcales de Dios}

Además de esto, la mayoría de las imágenes utilizadas en los textos canónicos de las religiones monoteístas, en las oraciones y en las teologías para hablar de Dios, dirigirse a él o representarlo, se relacionan con el poder, con el poder absoluto, e imponen relaciones de sumisión hacia los creyentes. Entre las más usuales cabe citar las siguientes: Rey, Príncipe, Juez, Justiciero, Señor, Señor de los Ejércitos, Soberano, Creador de Cielo y Tierra, Omnipotente, Soberano, Padre, Pastor, Guerrero, etc. Se aplican a Dios atributos varoniles en grado de excelencia, como la omnipotencia, la omnisciencia, la omnipresencia, la providencia, incluso la violencia. Tales imágenes y atributos no son otra cosa que distintas expresiones de una misma ideología, la del patriarcado, que legitiman religiosamente el poder de los varones como poder absoluto.

La hermenéutica feminista interreligiosa debe de-construir esas imágenes porque proyectan sobre Dios los atributos varoniles, que a su vez, se elevan a la categoría de normativos, generan en los seguidores de cada religión actitudes de sumisión y dependencia, y no fomentan una relación interpersonal. Especialmente crítica se muestra la teología feminista con la 
imagen de "padre", ausente del texto coránico y utilizada pocas veces en la Biblia judía. Se trata de una imagen que impone actitudes de obediencia y sumisión, de las que abusa la religión autoritaria (cf. TAMAYO-ACOSTA, 2003).

Ante estas imágenes, la teóloga alemana Dorothee Sölle se pregunta con una indignación no contenida:

¿Por qué los seres humanos adoran a un Dios cuya cualidad más importante es el poder, cuyo interés es la sumisión, cuyo miedo es la igualdad de derechos? Un ser a quien se dirige la palabra llamándole 'Señor', más aún, para quien el poder por sí solo no es suficiente, iy los teólogos tienen que asignarle la omnipotencia! ¿Por qué vamos a adorar y amar a un Ser que no sobrepasa el nivel moral de la cultura actual determinada por varones, sino que además la desestabiliza? (SÖLLE, 1996, p. 29).

Las tres religiones monoteístas: judaísmo, cristianismo e islam, que tuvieron en sus orígenes una clara orientación liberadora, sufrieron un proceso de esclerosis y hoy poseen numerosos y profundos rasgos de patriarcalización, que se dejan sentir en su organización, pero también en el imaginario religioso y en la mentalidad de cada creyente. Llevaron a cabo una masculiniziacón de Dios en tres direcciones: presentando a Dios con un lenguaje androcéntrico, eliminando los cultos matriarcales y relegando aquellas imágenes de Dios relacionadas con la naturaleza. El resultado final de ese proceso masculinizador de Dios fue la divinización del varón. "Si Dios es varón, el varón es Dios", afirma certeramente Mary Daly.

Pues bien, la hermenéutica feminista despatriarcaliza a Dios y recupera aquellas imágenes de la divinidad que tienen que ver con la vida, la amistad, el amor, la clemencia, la com-pasión, la beneficencia, la indulgencia, la comprensión, la generosidad, la ternura, el agradecimiento, la confianza, el perdón, la protección, la cercanía, la acogida, la solicitud, la justicia, la equidad, etc. Muchos de los 99 nombres de Dios en El Corán se refieren a estas actitudes. Por ejemplo: el vivificador, el clemente, el misericordioso, el benéfico, el generoso, el tierno, el agradecido, el confidente, el protector, el paciente, el indulgente, el cercano, el acogedor, el equitativo; las relacionadas con la naturaleza, como agua de vida, luz, viento vivo, que expresan la unidad con el todo, y no la sumisión al todo; las que establecen relaciones entre el ser 
humano y la divinidad no mediadas por la sumisión, sino por la amistad, el amor, la sociabilidad, la hermandad-sororidad.

Por eso, apunto a la necesidad de una correcta articulación entre la hermenéutica feminista interreligiosa y los movimientos de emancipación, pues toda hermenéutica se hace desde un determinado lugar social y religioso, que condiciona notablemente la lectura de los textos. En el caso de la hermenéutica feminista interreligiosa el lugar social desde donde interpretar los textos son los movimientos sociales, y muy especialmente las organizaciones que luchan por la igualdad, la justicia de género y la emancipación de las mujeres y de cuantas personas y colectivos se encuentran marginados. Es necesario, por tanto, que exista una correspondencia entre la lectura de los textos religiosos y la militancia en las organizaciones que luchan contra el patriarcado instalado en las religiones y en la sociedad, y que las tradiciones religiosas emancipatorias, la mayoría de las veces ocultadas, silenciadas y eliminadas, contribuyan a la construcción de comunidades religiosas y humanas no discriminatorias.

Un ejemplo luminoso de dicha articulación se encuentra en la Biblia de las mujeres antes citada, que fue escrita por mujeres vinculadas primero al movimiento de liberación de la esclavitud de las personas afrodescendientes y después al movimiento sufragista en defensa del derecho al voto de las mujeres en Estados Unidos. Algunas de estas mujeres, como la directora de la obra, Elizabeth Cady Stanton, fueron las que convocaron la Asamblea de Seneca Falls en 1848 donde se aprobó la Declaracón de sentimientos. Otro ejemplo de articulación correcta entre hermenéutica feminista y movimientos de liberación de las mujeres es más reciente: el de un colectivo de monjas católicas religiosas pertenecientes a diferentes Congregaciones, que se sumó a la huelga y a las manifestaciones del 8 de marzo de 2019. Lógicamente la interpretación que estas mujeres hacen de los textos sagrados deja de estar al servicio del patriarcado y se pone al servicio de una sociedad fraterno-sororal.

El texto se lee siempre desde un contexto, desde una tradición cultural. Es lo que llama Bultmann la pre-comprensión. Así se evita toda lectura fundamentalista legitimadora de las prácticas patriarcales, aplicando el círculo hermenéutico o, si se prefiere, el triángulo hermenéutico: de la experiencia al texto y de ésta a la experiencia, en una circularidad dinámica y re-creativa. 
Preguntar al texto desde nuestro hoy, nuestras inquietudes, problemas, esperanzas en la clave hermenéutica feminista.

Como la hermenéutica feminista estudia el rol jugado por los textos sagrados en la cultura patriarcal contemporánea y considera que debe impedirse la proclamación de los textos sexistas y patriarcales, violentos y discriminatorios en las celebraciones religiosas, así como la enseñanza de estos en la educación religiosa de los niños y niñas, de los jóvenes y de las personas adultas, esos textos no pueden ser considerados normativos en todo tiempo, lugar y cultura para las personas creyentes y para las instituciones religiosas, sino que han de considerarse expresión de la mentalidad en que fueron escritos (Cf. TAMAYO-ACOSTA, 2009). En la educación religiosa, en el culto, en la recitación personal y en la praxis deben privilegiarse aquellos textos que defienden la opción por las personas y los grupos excluidos, que ofrecen una visión liberadora de la vida y que abogan por la igualdad, una igualdad no clónica, sino que respete las diferencias, pero sin caer en las desigualdades de género. Por eso, la hermenéutica feminista utiliza el análisis histórico-crítico para ir más allá de los textos androcéntricos y recuperar la historia de las mujeres que se encuentra detrás del texto. No se olvida de los sufrimientos de nuestras antepasadas que lucharon por la libertad y la liberación tanto de ellas como de los sectores oprimidos, sino que recuerda ese sufrimiento y sus luchas con toda su fuerza subversiva.

Reivindica las visiones y los sufrimientos de los muertos, de las víctimas del sistema, y genera actitudes de solidaridad con los sufrimientos y las esperanzas de las mujeres en el pasado, en el presente y en el futuro, es decir, con las víctimas del patriarcado. La memoria de estas mujeres es ya en sí un acto de rehabilitación, de reconocimiento, de reparación, de devolución de la dignidad negada, y una denuncia de la inhumanidad e inmisericordia del sistema patriarcal (cf. TAMAYO-ACOSTA, 2003).

Propone, a su vez, modelos teóricos para la reconstrucción histórica que sitúa a la mujer en el centro de la teología y de la comunidad creyente, haciendo así una hermenéutica de la actualización creativa: una nueva característica de esta interpretación consiste en introducir a las mujeres en la historia bíblica, vetero y neo-testamentaria, y coránica, a reconocer su compromiso activo en la historia de la liberación. Tarea importante a este 
respecto es recontar las historias descritas en los textos sagrados desde una perspectiva feminista a través de la imaginación artística, la creatividad literaria, la música, la danza y otros recursos y lenguajes. De esa manera, las mujeres silenciosas y silenciadas recuperan su voz (cf. TAMAYO-ACOSTA, 2009) y se hacen audibles en la esfera pública, las mujeres invisibles e invisibilizadas se tornan visibles, las mujeres ausentes se hacen presentes, las mujeres marginadas y excluidas asumen el protagonismo como actoras de la historia, guías de los pueblos y dueñas de su propio destino.

\section{Una (necesaria) hermenéutica decolonial}

Las feministas del Sur Global, a partir de las experiencias de las mujeres de dicho ámbito geocultural, cuestionan con contundencia la interpretación que el feminismo del Norte global en general hace de la opresión de las mujeres solo desde el dualismo de género: los varones como opresores y las mujeres como oprimidas. Lo que constatan en sus propios entornos de pobreza y marginación es que las mujeres pertenecientes a etnias, religiones, naciones y clases subordinadas se sienten más oprimidas por las mujeres blancas privilegiadas que por los varones de la clase, etnia, nación o religión a la que pertenecen (cf. TAMAYO-ACOSTA, 2003).

Por eso la hermenéutica feminista debe articularse con otras hermenéuticas que permiten una lectura multidimensional, como la antropología cultural, la historia social, la historia política, la perspectiva económica, la ecología, con otras categorías eurísticas, como etnia, clase, cultura, religión, edad, nación, identidad sexual, pueblo; y con otras marginaciones, como la étnica, la social, la política, la religiosa, ecológica, la discriminación por identidades sexuales otras, etc. En realidad, las distintas marginaciones no se dan por separado y en paralelo, sino entrecruzadamente y en racimo.

La alternativa descolonizadora consiste en optar por una interpretación contextual en todos los terrenos que tenga en cuenta las plurales identidades culturales, espiritualidades, religiosas, étnicas, morales y cosmovisionales y los diferentes feminismos periféricos o decoloniales, cuyo objetivo es decolonizar el pensamiento feminista eurocéntrico hegemónico y subrayar la 
interseccionalidad de etnia, cultura, clase, género, identidad afectivo-sexual, etc.

El colonialismo no es un periodo histórico superado, un fósil inerme. Es una semilla que aún da sus frutos, reproduciendo una característica administración del pensamiento y sustentando un sistema de extracción de la mayoría de explotación del planeta... Aunque el sistema político de los imperios coloniales en sentido estricto quedó felizmente en el pasado, sus secuelas están presentes en las nuevas formas de imperialismo económico y político (y religioso, añado yo) liderado por capitalistas neoliberales en todos los rincones del mundo. Esta globalización tan trillada tiene efectos perversos para las mujeres. Aunque ciudadanas, estas dinámicas nos están empujando hacia una mayor pobreza, más responsabilidades nuevas, formas de migración, nuevas formas de control y violencia (SUÁREZ; AÍDA, 2008, p. 31).

El colonialismo sigue vivo y activo en la hermenéutica de los textos sagrados y tiende a imponer una lectura de estos conforme a las categorías de la cultura dominante, de las religiones mayoritarias y del poder hegemónico. Es necesario avanzar en dirección a la descolonización de la hermenéutica feminista, dominada todavía hoy por la epistemología, las categorías y los modelos culturales del llamado "feminismo occidental", si bien huyendo de los estereotipos sobre este feminismo, y renunciar a todo acto de imperialismo o racismo hermenéutico. Un buen apoyo para la hermenéutica decolonial de los textos de las tres religiones monoteístas se encuentra en la obra de María Lugones en torno a colonialidad y género y feminismo decolonial y su propuesta de un pensamiento de frontera feminista (LUGONES, 2008; 2011).

\section{Conclusión}

Como observa certeramente Elisabeth Schüssler-Fiorenza, las estructuras de la opresión de la mujer, además de múltiples, son multiplicativas. El sexismo se refuerza por el racismo; y la suma de ambos se multiplica por la diferencia de clase y por el colonialismo. Una hermenéutica feminista integral debe estar muy atenta a cómo se da también en los textos sagrados de las religiones ese carácter multiplicador de las estructuras de dominación de la mujer (cf. TAMAYO-ACOSTA, 2003). 
Por fin, la hermenéutica feminista de los textos sagrados no es asunto de una sola religión, sino de todas las religiones. Tenemos que construirla juntos. En la interpretación interreligiosa en perspectiva de género habría que seguir la sabia observación de Antonio Machado: “¿Tu verdad? No. La verdad. Y ven conmigo a buscarla (cf. TAMAYO-ACOSTA, 2009). La tuya, guárdatela". Esa es la gran tarea que nosotros, hombres y mujeres que nos dedicamos al estudio de los libros sagrados de las diferentes tradiciones religiosas, tenemos entre manos y no podemos descuidar, pues queremos construir en el interior de las religiones y en las sociedades donde estas están insertas, comunidades de iguales no sometidas a las discriminaciones que imponen el patriarcado, el sexismo, el colonialismo, el nacionalismo, el clasismo y el etnocentrismo.

\section{Referencias}

LUGONES, M. Colonialidad y género. Tabula Rasa, n. 9, p. 73-105, 2008.

LUGONES, M. Hacia um feminismo descolonial. La manzana de la discordia, v. 6, n. 2, p. 105-117, 2011.

SÖLLE, D. Reflexiones sobre Dios. Barcelona: Herder, 1996.

STANTON, E. C. (ed.). La Biblia de la mujer. Traducción de J. Teresa Padilla Rodríguez y María Victoria Lopez Pérez y prólogo a la edición española de Alicia Miyares. Madrid: Cátedra, 1997.

STEINER, G. Aprés Babel: Une poétique du dire et de la traduction. Paris: Albin Michel, 1978.

SUÁREZ, L. N.; AÍDA, R. H. (eds.). Descolonizando el feminismo: Teorías y prácticas desde los márgenes: Madrid: Cátedra, 2008.

TAMAYO-ACOSTA, J. J. Hacia un paradigma teológico universal en clave de liberación. San José: DEI, 1998.

TAMAYO-ACOSTA, J. J. Islam, cultura, religión y política. Madri: Trotta, 2009.

TAMAYO-ACOSTA, J. J. Nuevo paradigma teológico. Madri: Trotta, 2003. 
TRACY, D. Pluralidad y ambigüedad: Hermenéutica, religión, esperanza. Madrid: Trotta, 1997.

RECIBIDO: $26 / 10 / 2020$

RECEIVED: $10 / 26 / 2020$

APROBADO: 15/02/2021

APPROVED: 02/15/2020 